\title{
Mutilação genital e psicose
}

\section{Genital Mutilation and Psychosis}

\author{
David Souza Lima ${ }^{1}$ \\ Kamila PRIOR ${ }^{1}$ \\ RICARDO UCHIDA ${ }^{1}$ \\ SÉrgio Brotto ${ }^{1}$ \\ Regiane Garrido ${ }^{1}$ \\ SÉrgio Tamai ${ }^{1}$ \\ Marsal Sanches ${ }^{1}$
}

\begin{abstract}
Resumo
A automutilação em pacientes psiquiátricos não é incomum, podendo estar relacionada a crenças religiosas, impulsividade, abuso de substâncias e sintomas psicóticos. Relatos de mutilação genital em pacientes esquizofrênicos são encontrados na literatura médica. Encontra-se aqui descrito um caso de automutilação genital em um paciente de 42 anos de idade, portador de esquizofrenia.
\end{abstract}

Palavras-chave: Pênis, automutilação, amputação, esquizofrenia, psicose.

\begin{abstract}
Self-mutilation in psychiatric patients is not uncommon, and may result from religious beliefs, impulsivity, substance abuse and psychotic symptoms. Reports of genital mutilation among patients with schizophrenia can be found in medical literature. We described a case of genital self-mutilation in a 42 -year-old schizophrenic patient.
\end{abstract}

Key words: Penis, genitalia, self-mutilation, amputation, schizophrenia, psychosis.

\section{Introdução}

O comportamento automutilador em pacientes psiquiátricos não é incomum, variando largamente no que se refere à topografia e à gravidade das lesões. Atos complexos, como a auto-amputação de membros, parecem ocorrer com freqüência bem menor. Há, por exemplo, referência a apenas 11 casos de auto-amputação intencional de membros superiores na literatura médica (Schlozman, 1998). Diversos fatores são citados como associados a maior risco de automutilação, tais como crenças religiosas específicas, abuso de substâncias, impulsividade, sintomatologia psicótica e presença de diagnóstico comórbido em eixo II, particularmente transtorno borderline de personalidade (Favazza e Rosenthal, 1993; Favazza, 1998; Schlozman, 1998; Gunderson e Ridolfi, 2001).

Relatos de um tipo específico de auto-mutilação, a mutilação genital, são encontrados na literatura (Martin e Gattaz, 1991; Zislin et al., 2002). Embora não se disponham de dados exatos referentes a prevalência da automutilação genital masculina, Zislin et al. (2002) fazem referência a 110 casos na literatura médica, e pacientes esquizofrênicos correspondem a um grupo particularmente suscetível a atos desta natureza (Walter, 1993). Nestes, parece haver uma tendência a repetição do comportamento automutilador, especificamente quando ocorre interrupção do tratamento farmacoterápico (Martin e Gattaz , 1991). 
Encontra-se aqui relatado um caso de automutilação peniana em um paciente portador de esquizofrenia.

\section{Relato do caso}

Paciente de 41 anos, sexo masculino, portador de quadro psicótico crônico, compatível com esquizofrenia paranóide, de acordo com critérios diagnósticos do DSMIV (American Psychiatric Association, 1994). Vinha realizando seguimento ambulatorial, com uso de diversos antipsicóticos, sempre com remissão parcial dos mesmos e inúmeras recaídas. Nos últimos anos, vinha fazendo uso de penfluridol $10 \mathrm{mg}$ por semana. Aproximadamente dois meses antes da admissão no Centro de Atenção Integrada à Saúde Mental (CAISM) da Irmandade da Santa Casa de Misericórdia de São Paulo, passara a fazer uso irregular da medicação, tendo evoluído com desorganização do comportamento, alucinações auditivas, roubo e irradiação do pensamento. Apresentava delírios de influência (dizia ser controlado e influenciado por espíritos que adentravam seu corpo) e de grandeza (relatava que Deus havia concedido a ele poderes de cura).

Quinze dias antes da admissão, o paciente amputou o próprio pênis, obedecendo a alucinação auditiva de comando, utilizando para isso uma faca de cozinha. Depois dos cuidados cirúrgicos, o paciente foi internado na enfermaria de psiquiatria do CAISM, onde passou a receber medicação antipsicótica. Foi medicado inicialmente com risperidona $10 \mathrm{mg}$ ao dia por um período de 60 dias, com pouca melhora da sintomatologia psicótica. O paciente relatava, desde a entrada, novos planos de automutilação e ideação suicida. Não demonstrava qualquer arrependimento por seu ato, ao qual atribuía significado delirante. Afirmava que vinha trabalhando, por telepatia, com um sistema de computadores, e que teria ocorrido um bloqueio neste sistema. Segundo o paciente, se o referido sistema não fosse desbloqueado, pessoas perderiam seus empregos e outros acontecimentos funestos poderiam ocorrer. A autocastração seria, de acordo com o paciente, a única maneira de desbloquear o sistema de computadores. Esta idéia era reforçada por alucinações auditivas: o paciente relatava ter ouvido, em cinco ocasiões diferentes, a voz de Deus, ordenando-lhe que se castrasse, como um "sacrifício". Consumado o ato, o paciente contava ter experimentado grande alívio já que, segundo suas crenças delirantes, o sistema havia sido "imediatamente desbloqueado".

Diante da ausência de resposta à medicação utilizada, esta foi substituída por clozapina. A medicação foi progressivamente aumentada até a dose de $700 \mathrm{mg}$ ao dia, e mantida por um período de três meses. Não foi observada melhora significativa, com persistência da ideação suicida e do desejo de automutilação. Por esta razão, a dose da clozapina foi reduzida para $300 \mathrm{mg}$ ao dia e o paciente passou a receber, em associação ao tratamento medicamentoso, eletroconvulsoterapia (ECT), na freqüência de três vezes por semana.

Após 12 sessões de ECT, houve melhora da ideação suicida e dos planos de automutilação, embora parte das idéias delirantes ainda persistissem. A dose da clozapina foi então, novamente aumentada.

Passados oito meses de internação, o paciente recebeu alta da enfermaria com $700 \mathrm{mg}$ de clozapina ao dia.Apresentava melhora parcial dos sintomas psicóticos. Foi encaminhado para prosseguir com o tratamento em regime de hospital-dia, tendo sido orientada vigilância intensiva em domicílio por parte dos familiares. Ao longo de um período de seis meses de seguimento após a alta, não foi observada recorrência do comportamento automutilador. O paciente manteve-se indiferente e sem relatar qualquer arrependimento em relação ao ocorrido embora, após a melhora do quadro psicótico, tenha passado a relatar explicação alternativa para seu ato. Afirma que, na época da automutilação, seu corpo era habitado por espíritos, e que estes lhe teriam ordenado que se castrasse como forma de perpetuar seu "trabalho" com o sistema de computadores.

\section{Discussão}

O presente relato ilustra o fenômeno da automutilação genital em um paciente esquizofrênico. Além da presença de sintomas psicóticos, a literatura médica parece apontar para outros diagnósticos relacionados à ocorrência de automutilação genital, dentre os quais podemos citar: quadros depressivos, intoxicação alcoólica e alterações da identidade sexual (Martin e Gattaz, 1991). Entretanto, conviç̧ões religiosas ou culturais também podem estar envolvidas na origem deste comportamento (Master e Santucci, 2003) e o limite entre estas crenças e a presença de patologia psiquiátrica pode ser de difícil delineamento.

Não obstante o longo período de evolução da doença mental do paciente, previamente ao episódio relatado, nunca mencionara qualquer idéia de automutilação. Além disso, apesar da persistência dos sintomas psicóticos durante o período de internação e seguimento após a alta, não foi observada recorrência do comportamento automutilador. Estes dados suscitam questões relativas a dificuldades na prevenção da recorrência de automutilações. É possível a identificação de indicadores sugestivos de um maior risco de automutilação? Em que momento este risco deve ser considerado alto o suficiente para justificar intervenções mais incisivas, como por exemplo internações psiquiátricas? Ainda que estas perguntas não possam ser facilmente respondidas, é importante que estratégias visando a redução deste risco sejam discutidas diante de cada caso de automutilação.

Na grande maioria das vezes, estes pacientes serão atendidos inicialmente em serviços não-psiquiátricos, e medidas imediatas (vigilância por parte da enfermagem, 
contenção mecânica e/ou química), visando à prevenção do comportamento automutilador devem ser tomadas, medidas estas que devem ser continuadas durante a internação psiquiátrica, caso esta seja indicada.

Por ocasião da alta hospitalar, é recomendável que estes pacientes sejam mantidos sob seguimento psiquiátrico intensivo. Orientações quanto à vigilância por parte de familiares devem ser dadas, e o paciente deve ser levado para atendimento psiquiátrico de urgência diante de qualquer suspeita de que uma nova tentativa de automutilação se encontre iminente, ainda que não verbalizada pelo paciente.

\section{Referências bibliográficas}

American Psychiatric Association. - Diagnostic and Statistical Manual of Mental Disorders, 4a ed. Washington DC: American Psychiatric Press; 1994.

Favazza, A.R.; Rosenthal, R.J. - Diagnostic Issues in SelfMutilation. Hosp Community. Psychiatry44(2): 134-40, 1993.

Favazza, A.R. - The Coming of Age of Self-Mutilation. J Nerv Ment Dis 186(5): 259-68, 1998.

Gunderson, J.G.; Ridolfi, M.E. - Borderline Personality Disorder. Suicidality and Self-Mutilation. Ann N Y Acad Sci 932: 61-73, 2001.

Martin, T.; GatTAz, W.F. - Psychiatric Aspects of Male Genital Self Mutilation. Psychopathology 24: 170-8, 1991.
Master, V.; Santuccl, R. - An American Hijra: a Report of a Case of Genital Self-Mutilation to Become India's “Third Sex". Urology 62(6): 1121, 2003.

Schlozman, Steven C. - Upper-Extremity Self-Amputation and Replantation: 2 case Reports and a Review of the Literature. J Clin Psychiatry 59: 681-6, 1998.

Walter, P.J.; Krauss, D.J.; Nsoull, I.S. Repeat Male Genital Self Mutilation Precipitated by Urinary Complications of Prior Repair. The Journal of Urology 149: 1551-52, 1993.

ZISLIN, J.; KATZ, G.; RASKIN, S. et al. - Male Genital Self Mutilation in the Context of Religious Belief: the Jerusalém Syndrome Transcultural. Psychiatry 39(2): 257-64, 2002. 